\title{
Niños en la ciudad: multitud, masas e infancia en la \\ narrativa chilena (1930-1965)*
}

Children in the City: Mass Culture and Childhood in Chilean Narrative (1930-1965)

\section{Claudia Darrigrandi}

Universidad Adolfo Ibáñez

cmdnfl@gmail.com

\begin{abstract}
El siguiente artículo se enfoca en las relaciones entre los conceptos de multitud, masas, cultura de masas e infancia en tres novelas chilenas: Hijuna (1934) y La fábrica (1935), escritas por Carlos Sepúlveda Leyton, y El río (1962) de Alfredo Gómez Morel. Si en las novelas Sepúlveda Leyton se plantea cómo los niños en el sistema escolar son sometidos a procesos de homogenización, escolarización y masificación para la novela de Gómez Morel se arguye que el fracaso del sistema escolar produce subjetividades que, si bien escapan de los procesos de homogeneización del Estado, están mediadas por la cultura de masas.
\end{abstract}

Palabras clave: Niños-masas-cultura de masas.

This article discusses the manner in which the concepts of mob, masses, mass culture and childhood are related in three Chilean novels: Hijuna (1934) and La fábrica (1935), by Carlos Sepúlveda Leyton, and El río (1962), by Alfredo Gómez Morel. In Sepulveda Leyton's novels, the author explores how children are subjected to homogenization, schooling and massification processes. On the other hand, Gomez Morel argues that schooling and massification processes. On the other hand, Gomez Morel argues that the State's homogenization processes- are mediated by mass culture.

Key words: Children, masses, mass culture. 
Sentado dentro de un auto frente al Museo Nacional de Bellas Artes un hombre le dice a su amante, Blanca, que debe dejarla para evitar un futuro lleno de sufrimiento. En ese contexto, la narradora interrumpe el discurso masculino señalando: "Varios chiquillos andrajosos cruzaron el puente y se perdieron en una de las calles, más allá del río. La atmósfera quedó cargada de un temblor de risas" (171). En esta escena de la novela chilena Islas en la ciudad escrita por María Elena Gertner (1957), los "chiquillos andrajosos" no tienen un rol protagónico. Invisibles en esta historia, solo aparecen para "decorar" el amargo momento en que Blanca, una joven de 18 años enamorada de un hombre casado, es abandonada, quedando así desamparada como los niños del río. Lucy Lippard señala que "al igual que los indígenas durante el siglo XIX del mundo occidental, los sin casa o vagabundos son percibidos como la parte insignificante o desdeñable del paisaje" (273, la traducción es nuestra). Islas en la ciudad no privilegia los espacios públicos como tampoco las problemáticas sociales que se visibilizan en estos, en cambio, construye un mapa sensible de la interioridad burguesa urbana. En este contexto, el "temblor de risas" que queda tras el paso de los chiquillos andrajosos, invade la intimidad de los amantes burgueses y tiñe el ambiente de emociones ambiguas: entre el temor, el nerviosismo y la algarabía. En este paisaje que funciona como telón de fondo, si bien en términos de imagen se condice con lo propuesto por Lippard, la presencia de los niños deja una huella. Refuerza las emociones de la escena y genera un estado de alerta: "el temblor de risas" anuncia también un pequeño peligro.

Numerosos son los estudios que explican la desconfianza social hacia los niños y niñas sin casa ni familia, tanto en Europa como en las Américas, en particular desde la segunda mitad del siglo XIX en las ciudades industrializadas o en vías de industrialización. Para el caso chileno, el historiador Jorge Rojas Flores en la presentación de su libro Moral y prácticas cívicas en los niños chilenos, 1880-1950 señala que su investigación estuvo motivada por "el temprano temor que se despertó hacia los niños que no lograban ser vinculados a los mecanismos de formación cívica" (9). Asimismo, una mirada a la prensa nacional de las primeras décadas del siglo XX revela la ansiedad y preocupación que generaba la vagancia infantil, asunto que se intentó contrarrestar por medio de la promulgación de la Ley de Instrucción Primaria Obligatoria en septiembre de 1920.

Los infantes en las calles han sido observados por la sociedad burguesa a través del lente del temor y conflictos sociales. En las siguientes páginas propongo analizar la representación de los niños protagonistas de un corpus de novelas chilenas como parte de las multitudes o masas en la ciudad de Santiago. Tras una breve alusión inicial a la novela El roto de Joaquín Edwards Bello (1920), donde la escritura del niño protagonista que callejea y no se adscribe a los sistemas de normalización social ironiza la mirada oligárquica que observa al sujeto popular como una amenaza, se pasa a reflexionar en torno a cómo cambia la representación de los niños de los sectores bajos o marginales cuando quien narra proviene de una nueva generación de escritores que se inscribieron en el campo literario debido a su participación en la maquinaria educacional, entendida especialmente como mecanismo de disciplinamiento, de la primera mitad del siglo XX. De esta forma, se plantea que si el niño roto de la novela de Edwards Bello sería una muestra 
de lo que en el cambio de siglo se entendía como "multitud" o "masa", los vínculos entre niñez y las nociones de multitud, masa y sociedad de masas se complejizan en las novelas Hijuna (1934) y La fábrica (1935), escritas por Carlos Sepúlveda Leyton, y El río (1962) de Alfredo Gómez Morel, todas de corte autobiográfico. Los narradores encarnan las voces de niños y en el gesto autobiográfico los autores revisan y ficcionalizan su pasado infantil. Estas tres novelas, si bien fueron publicadas entre 1930 y 1962, están ambientadas en las primeras tres décadas del siglo, periodo de fuertes movimientos sociales cuyos protagonistas son visibilizados por las elites con los rasgos de las multitudes o las masas.

Como mencioné anteriormente, si los niños, en particular los callejeros y de sectores populares, produjeron recelo y preocupación entre el mundo adulto, lo mismo ha ocurrido con las multitudes o masas. En cuanto a estos dos últimos términos, revisando la aplicación de los conceptos masa, multitud populacho y muchedumbre en el marco de la segunda mitad del siglo XIX hasta las primeras décadas del siglo XX, la crítica argentina Graciela Montaldo plantea que: "[esos] nombres no designan exactamente a los mismos sujetos en los libros de los numerosos intelectuales que se dedican al tema. Esa misma proliferación habla de un sujeto difícil de definir, relativamente amorfo y siempre peligroso" ("Hombres de la multitud y hombres de genio" 125). Destaco el carácter "amorfo y siempre peligroso" que señala Montaldo porque ejemplifica cómo eran percibidos los sectores populares y los cada vez más visibles grupos proletarios por parte de las elites en el contexto chileno. Por su parte, en un capítulo de su libro Otro territorio. Ensayos sobre el mundo contemporáneo, Renato Ortiz también realiza un minucioso análisis del origen, usos y transformaciones de los términos multitud, masa y cultura de masas $^{1}$. En cuanto al término multitud, Ortiz puntualiza que desde el siglo XIX europeo se entendía que estaba compuesta de "'bárbaros', 'salvajes', grupos enteramente al margen de la civilización" (95). Según el autor, el concepto de multitud, surgido a partir de la industrialización y las reformas políticas europeas del siglo XIX, estaba asociado a "mendigos, trabajadores, marginales, prostitutas, inmigrantes y obreros" (95). Además, agrega que "el alcoholismo, la criminalidad, las enfermedades epidémicas, en suma, el desorden, serían sus atributos esenciales" (95-96).

Según Andrea Jeftanovic en su libro Hablan los hijos. Discursos y estéticas de la perspectiva infantil en la literatura contemporanea, desde finales de siglo XIX en Europa, y más claramente a partir del siglo XX en Latinoamérica, "confluye el retiro 'oficial' del niño mundo del trabajo, los avances en el conocimiento de la psiquis infantil y la masificación, acotada a los centros urbanos principalmente, de la escolaridad obligatoria... la escuela y la casa, habitada por una familia nuclear, comienzan a imponerse como los espacios legitimados" (22). En este sentido, cuando dejan de ser considerados como sujetos productivos, los niños fuera de la escuela y de la casa serán una muestra emblemática, así como la prostitución, el vagabundeo y el alcoholismo, de los problemas sociales urbanos. De este modo, los niños

1 Según Renato Ortiz el concepto "cultura de masas" en los años cuarenta ya era de uso corriente en Estados Unidos y a la idea de masas le antecede la de multitud (94-95). 
y niñas se convirtieron en figuras centrales para los proyectos nacionales, representando de esta forma un cuerpo en disputa por parte del Estado, la ley, las familias $\mathrm{y}$, a medida que avanza el siglo XX, también del mercado (21-35). Similar es el planteamiento de la historiadora Nara Milanich, quien en su libro Children of Fate: Childhood, Class, and the State in Chile, 18501930 plantea que "en momentos de conflicto social, los huachos pobres y marginalizados anunciaban el desorden social", lo que ponía en el debate público las leyes que regulaban la estructura familiar y la potestad de los niños (232-233, la traducción es nuestra). Tomando en cuenta estas ideas, sería pertinente indicar que los infantes que circulan por las calles de la ciudad son también parte de las masas/multitudes que, desde la mirada de la oligarquía y burguesía, amenazan el orden social de inicios de siglo. En consecuencia, se convierten en seres doblemente peligrosos: como niños y como parte de las masas. Sin embargo, aunque las nociones de multitud o masas tienden a la indefinición de un cuerpo social, es un ejercicio interesante intentar visibilizar en estas a los niños.

En el contexto chileno, una de las novelas fundacionales sobre las representaciones de la infancia vinculada a los sectores populares y al crecimiento urbano es El roto de Joaquín Edwards Bello (1920). Este libro marca un hito en el pequeño mercado editorial de inicios del siglo XX al literaturizar el resquemor que producen las multitudes en los grupos hegemónicos. El protagonista, un niño que nace y crece en un prostíbulo de un barrio aledaño a la estación de ferrocarriles, que podría ser entendido, a su vez, como un representante de los sectores proletarios y las incipientes masas urbanas, su imagen y su historia terminan circulando en la prensa como "el caso Esmeraldo", como un delincuente, a pesar de no haber cometido ningún crimen. Aquí quisiera retomar nuevamente las ideas de Ortiz, que si bien se adscriben al contexto europeo, son identificables también al contexto latinoamericano. La novela de Edwards Bello se publica tras dos décadas de movimientos sociales en busca de mejoras en las condiciones laborales y de vida; 1920 es también el año en que es elegido presidente Arturo Alessandri con el apoyo de las "masas". El roto se publica cinco años antes de la promulgación de un nuevo proyecto constitucional que redefinió los parámetros de ciudadanía. Es decir, la tensión social entre la vieja oligarquía, los intereses burgueses y el nuevo proletariado fue una de las características más relevantes de la historia social urbana de inicios del siglo XX. Según el crítico, la idea de multitud, etnocéntrica y preconceptuosa, se desdobla en el plano político, pues el siglo XIX europeo asiste, también, a las luchas de clase, las reivindicaciones de las asociaciones de trabajadores, los conflictos políticos. Multitud se aplica, por lo tanto, a la clase proletaria emergente, a sus exigencias de participación política y ciudadana (96).

Aunque para Bernardo Subercaseaux la representación del protagonista como un receptáculo de lacras sociales, prejuicios y estigmatizaciones se inscribe en una novela que despliega una "decontrucción irónica del nacionalismo predominante" (Subercaseaux, Historia de las ideas 166), en el prólogo el autor señala que "Los cuadros crudos del roto, vienen a ser como esas fotografías de fieras que los turistas toman de noche en plena selva" (1, el énfasis es mío) dando cuenta del distanciamiento entre quien escribe y los nuevos sectores urbanos mediante la animalización del sujeto popular. 
Sin embargo, esta fotografía nocturna implica también la posible toma defectuosa 0 , al menos, borrosa.

A partir de los años treinta emergieron nuevos actores culturales provenientes tanto de los sectores populares como también de la clase media profesional que se unieron a ( $y$ también comenzaron a reemplazar a) una elite letrada con resabios decimonónicos que, salvo excepciones, había monopolizado la creación de los imaginarios urbanos. Asimismo, a partir de 1930 Santiago experimentó una expansión importante en sus límites como también un proceso modernizador sin precedentes (De Ramón). De mismo modo, es importante notar que para este periodo dos historiadores clásicos de la historia urbana, Armando de Ramón en su libro Santiago de Chile: historia de una sociedad urbana y José Luis Romero, para el contexto latinoamericano (Latinoamérica: las ciudades y las ideas), caracterizan el espacio urbano capitalino como una ciudad de masas que instala un nuevo panorama social y cultural diversificando el paisaje citadino. A partir de 1930 son las masas las que ocupan un lugar protagónico en la historia urbana latinoamericana y comienzan a publicar sus novelas autores que, a diferencia de Edwards Bello, no se identifican con las elites letradas tradicionales. Muchos de estos escritores como Nicomedes Guzmán, Luis Cornejo Gamboa y Carlos Sepúlveda Leyton están vinculados a los sectores obreros o periféricos de la ciudad. En este contexto, es relevante preguntarse qué ocurre con la representación de las multitudes o masas cuando el sujeto enunciante es parte de estas.

Hijuna es el sobrenombre del protagonista de la novela homónima cuyo nombre es Juan de Dios. Es el niño narrador que vive en un barrio donde la vida obrera se entrelaza con la presencia de un Estado cada vez más fuerte y cuya visibilización se materializa en la fábrica de cartuchos, la penitenciaría (cárcel) y la futura escuela. La novela da cuenta de su infancia en el barrio Matadero-Franklin, ubicado en lo que por esos años eran los límites de la ciudad y que fue escenario de una de las protestas más emblemáticas de inicio del siglo XX: la Huelga de la Carne de 1905. En este sentido, el barrio de Hijuna está habitado por lo que, según Ortiz se identificó como multitud en el cambio de siglo, es decir, por una "clase proletaria emergente [...] Considerada como un agrupamiento irracional, atávico, guiado por la exacerbación de los sentimientos [que para las elites] encarnaría la negación de los principios democráticos y la libertad humana" (96).

Como forma de incorporar esta masa a la organización social deseada por quienes administraban el Estado, a inicios del siglo XX la educación primaria y la formación de docente se convirtieron, al menos en los discursos modernizadores, en los vehículos más plausible para incorporar a los niños y niñas en los proyectos de construcción nacional y de ciudadanía. En este sentido, en la novela somos testigos de un entorno espacial y social mediado por la mirada del niño, cuya cotidianidad se ve alterada por la instalación de una escuela primaria que, de ningún modo, es fuente de felicidad para e niño-narrador: "Frente de cal y ladrillo, y fondo de fosa común: esa fue la escuela que asesinó la alegría de nuestro barrio" (93), anunciando de este modo una resistencia ante los procesos de escolarizacion y de homogeneización al que los niños chilenos estuvieron sometidos, especialmente, a partir 
de 1920 con la promulgación de Ley de Instrucción Primaria Obligatoria². Asimismo, como se anunció anteriormente, otro de los elementos relevantes en la apreciación del mundo por parte del niño Juan de Dios es el contexto de movilización social en el que se inscribe su infancia. Tanto en el norte del país por parte de los mineros como en Santiago se vive un ambiente de protestas, marchas y huelgas. La dificultad de los niños para comprender esos conflictos sociales no impide que perciban la magnitud de esos hechos de violencia. Entre sus conversaciones y juegos callejeros empatizan con la tristeza del ambiente: "Aquietados, volvemos a nuestra posición a la orilla de la pared $y$, en cuclilla, en la noche formamos un solo monton de sombras y pena" (134). Las individualidades de Perucho, Enrique e Hijuna se funden para conformar un objeto de difícil identificación, quizás "amorfo" en tanto "montón de sombras" si recordamos uno de los términos usados por Montaldo para definir la multitud. En este sentido, se refuerza la mirada de extrañeza que existe sobre la subjetividad infantil. Sin embargo, esa imagen con la que Hijuna se representa con sus amigos está marcada por la derrota y la pena. Por un lado, arrinconados en la pared, las posibilidades de arrancar o sobreponerse parecen pocas. Por otro, esa debilidad unida a la pena matiza cualquier síntoma de barbarización o una inminente peligrosidad. La presencia de la pena, en tanto sentimiento, suaviza la presencia y actuar de los instintos bárbaros característicos de las nociones de multitud desarrolladas en el fin de siglo (XIX-XX).

Según Ortiz, la multitud es "una aglomeración de personas en un determinado lugar", por lo tanto, es visible pero está compuesta de elementos heterogéneos, ningún vínculo social más profundo une a sus integrantes. De ahí su carácter de transitoriedad. La multitud posee un 'alma colectiva' porque sus miembros actúan en conjunto, pero es incapaz de generar una 'conciencia colectiva'. Los que participan en ella son desconocidos unos para los otros, nada los aproxima, tradición, valores, lazos familiares, ideología, o creencia'... la multitud presupone la dilución de las individualidades. Propicia un comportamiento irracional y emocional (99).

En las últimas páginas de la novela mientras se desencadenan los hechos de violencia debido a la Huelga de la Carne de octubre de 1905, Hijuna y sus amigos se unen a la multitud. Mientras se desarrolla el conflicto, el niño narrador señala: "ahora no somos más que sombras móviles en la negra sombra de la cerrazón" (141). Se destaca, una vez más, la imagen amorfa que proyecta el grupo de amigos de Hijuna y la anulación de la subjetividad de cada uno de ellos mientras son doblemente invisibles, porque son parte de la multitud y porque son niños infiltrados en un conflicto que solo entienden los adultos. Sin embargo, hay un intento por superar esa invisibilidad y cerrazón sin desmarcarse de la multitud. Entonces, emocionados por ser parte del enfrentamiento, los niños intentan dejar de ser "sombras móviles" y adquirir un poco más de protagonismo: "nos enseñoreamos y gritamos petulancias en contra de lo imaginado y a favor de lo que no sabemos qué. iAbajo! iAbajoo! iViva! iVivaa!" (141). Si en un primer momento los niños

2 Todas las citas de la novela Hijuna y de La fábrica de Carlos Sepúlveda Leyton provienen de la edición del año 2013 publicada por Sangría Editora. 
son un "montón de sombras" dominados por los sentimientos de la pena, imagen que invita al lector a compadecer más que temer, al calor del combate y dominados por la ignorancia, al querer adquirir protagonismo y movidos por sus instintos, devienen en multitud. La batalla entre huelguistas y represores continúa, "[r]ecula la masa y se atropella sin asunto ...Solo nosotros quedamos en la calle. Libres somos, y somos bien capaces de quebrar todos los faroles del mundo", señala Hijuna (143-144). Al separarse de la masa, él y sus amigos tienen la oportunidad de ser protagonistas de su propia lucha para superar la imagen de ser un "montón de sombras" o "sombras móviles". Es así que el narrador se presenta junto a Perucho y Enrique como sujetos envalentonados por los sucesos del día e influenciados por el actuar de la multitud "capaces de quebrar todos los faroles del mundo". Sin embargo, el comentario no pasa más allá de la amenaza de replicar lo que probablemente veían mientras ocurría la represión contra los huelguistas, porque antes que ser multitud, son niños. Los faroles quedan intactos.

La novela culmina con el fin de la infancia del narrador y su partida a la Escuela Normal, lugar donde ya no el niño, sino el adolescente Juan de Dios estudiará para ser profesor normalista. Las últimas páginas de Hijuna anticipan el proceso civilizatorio al que estará sometido Juan de Dios y que será e eje central de la siguiente novela de Sepúlveda Leyton, La fábrica: "Ya estoy empaquetado, embalado, listo para ir a la Escuela Normal. Todo yo -iel palomilla!- no soy más que una cosa acorde al Prospecto, un petimetre hecho lienza según modelo" (177). Como si fuera un producto saliendo de una huincha de la fábrica y que se dirige a otra etapa de la producción, el joven expresa su rechazo a ser una "materia prima" de la cual, finalmente, se moldeará un ciudadano útil que, a su vez, moldeará a otros, formando así una cadena de producción de ciudadanos. En pocas palabras, en Hijuna el niño deja de ser "solo montón de sombras y pena", es decir, parte de un cuerpo amorfo e infantil, para convertirse en un sujeto claramente identificable, "el estudiante normalista", pero que se produce en serie y como él hay muchos otros niños y jóvenes que, parafraseando al narrador, son "manufacturados" (284). Como un "petimetre hecho lienza según modelo" habrá muchos otros adolescentes más en su situación, recordando la producción en serie que caracteriza la industrialización comenzada a inicios del siglo XX. De este modo, esta nueva condición tampoco lo dota de una subjetividad en el mundo de los adultos.

En la segunda novela de Sepúlveda Leyton, La fábrica, si seguimos las definiciones de Ortiz, se hace mucho más visible la idea de masa, o más específicamente, de "sociedad de masas" en tanto, según el sociólogo, corresponde a un periodo en "que la masa de la población fue incorporada a la sociedad" (105) y cuyas identidades individuales pasaron por un proceso de dilución. La novela comienza con la llegada del joven narrador a la Escuela Normal de Preceptores donde, en sus palabras, "[...] somos un número. Un número negro sobre blanco, igual que bestias en la feria. Un número que nos controla y nos determina: un puño cerrado en el fichero de una fábrica. Todo el mundo arrellanado en mi juventud aplastada por el número, como en los hospitales" (La fábrica 223).

Haciendo eco de los procesos de producción masiva el narrador enfatiza la anulación de la subjetividad y el pensamiento crítico de los estudiantes 
de la Escuela Normal de Preceptores. Todos los nuevos estudiantes son: "un terno negro, nuevecito; una bolsa de cotí, y un tongo" (224). En este sentido, se observa la institucionalización de la ciudad por medio de la Escuela Normal, que adquiere características de dispositivo homogeneizador. Si el niño-multitud en Hijuna tiene un voz que intenta hacer escuchar durante los hechos de violencia de los que es testigo e interviene "a favor de unos y en contra de no sabe quién", en La fábrica destaca tanto la estatización de la ciudad como también su carácter policial, al señalar que la Escuela Normal "parece cárcel" (308) y donde Juan de Dios "tropiez[a] con el Reglamento" (308). El mundo del joven está limitado a memorizar y repetir, una y otra vez. Estando en clases, el profesor dice:

El que quiera salir y componer su conducta no tiene más que escribir cincuenta veces esta frase. Ha de ser con tinta y letra cuidada...

Yo, N.N.

N.N. es el nombre no expresado. Cada uno escribe su nombre, explicó.

Yo, N.N., alumno de primer año de la Escuela Normal de Preceptores de Santiago, confieso mi falta; pero, al mismo tiempo, confieso estar sinceramente arrepentido, y prometo, bajo la fe de mi palabra de honor, no reincidir en lo sucesivo (389).

Aunque cada uno deberá poner su propio nombre, el "Yo, N.N" enfatiza la idea de que, así como puede ser el protagonista, puede ser cualquier otro, da igual. Todo aquel que quiera que su castigo (que también es masivo, pues al parecer, no es un estudiante el que lo merece, sino todos) sea levantado debe ejecutar un ejercicio de repetición que atenta contra la propia reflexión sobre lo sucedido. El joven pierde su voz, la oportunidad de pensar, y debe seguir un molde que luego, ya siendo profesor, deberá imponer a otros, estableciéndose de esta forma una producción en cadena. No obstante, el joven Juan de Dios busca espacios para la sobrevivencia. En un encuentro entre Juan de Dios y el inspector de la escuela, este último le ordena al protagonista dejar de reírse a lo que este le responde:

\section{No, señor. Pensaba.}

Usted, iiiiPENSABA!!!!

Sí, señor. Estaba pensando en Napoleón.

iUsted pensaba en Napoleón! ... iPero eso es fantasear!

Y la fantasía es la loca de la casa. ¿Usted no sabe que la fantasía es la loca de la casa?

¿La loca de la casa? No, señor.

iCuádrese! Pero hay una camisa de fuerza para reducir a

esa loca, ila VOLUNTAD! (253).

Esta es una de las muchas escenas en la que el joven pierde su voz y, en esta oportunidad, es castigado sin su salida de domingo. El niño reconoce las limitaciones a las que está sujeto por su edad y por la institución a la que pertenece: "La gente grande es la que piensa. Los muchachos no piensan, las piedras no piensan" (232). Sin embargo, por medio de "la loca 
de la casa" Juan de Dios sobrevive la experiencia de la Escuela y la ficcionaliza: los estudiantes más avanzados son unos bigotes que caminan por los pasillos, el mozo del comedor es un saco blanco que les sirve la comida y uno de los profesores, más que profesor, es una aceituna hablante, por mencionar algunos ejemplos.

Edwards Bello como Sepúlveda Leyton inscriben sus novelas en las periferias de la ciudad. Sin embargo, a diferencia de El roto, en las novelas de Sepúlveda Leyton el que narra es un niño que participa de la experiencia de la multitud y que, poco a poco, al estar circunscrito en los procesos de escolarización, entra a ser parte de la "sociedad y cultura de masas". Es decir, a la formación de preceptores a inicios del siglo XX chileno se la imagina como si fuera una producción industrial, como bien lo dice el título de la novela y su narrador: "he venido a que me manufacturen" (284). La masa aquí es cantidad, homogeneidad y elisión de subjetividad. Si bien en algunos pasajes de La fábrica la representación de los jóvenes en la escuela adquiere connotaciones animalescas, "nos revolvemos como un rebaño de ovejas, y nos falta solo balar, acorralados en el angosto pasillo", esta cobra importancia en la descripción de las condiciones bajo las que son formados los futuros profesores más que en una bestialización del sujeto ante la cámara del turista que antecede la novela de Edwards Bello (La fábrica 244).

Otro es el lugar de enunciación de Alfredo Gómez Morel autor de $E$ río (1962). La novela está centrada en el periplo de un niño/adolescente (que en la novela recibe tres nombres, pero para el caso de este artículo lo llamaremos Toño) por la ciudad y su determinación por formar parte de hampa santiaguina. Detrás de la decisión de vivir en el río hay una historia de maltrato, abandono y abusos de todo tipo (sexuales, psicológicos, físicos, etc.) experimentados tanto en el hogar, por parte de su madre, como también en el internado La Gratitud Nacional, lugar al que fue por decisión de su padre y donde es abusado sexualmente por dos de los sacerdotes que administran el colegio, razón por la cual decide abandonarlo, aunque Manuel Vicuña destaque los beneficios de "[s]er el favorito, el efebo de dos curas que se disputan sus favores, le significará gozar de privilegios que él mismo expandirá, combinando el descaro y el oportunismo. 'Gané bastante con todo eso', recuerda" (106).

En la novela El río, la cuenca del río Mapocho se constituye como un espacio sociocultural paralelo a la vida en la ciudad donde encuentra refugio y un modo de subsistir los infantes que han huido de sus casas o que, de alguna u otra forma, han sido descartados por la sociedad. Sin embargo, en el río se replican algunos principios ordenadores de la civitas: "Como la ciudad, el río también tiene sus jerarquías y los delincuentes son celosísimos de ellas" (162). Unos pueden ser "pelusas", pero otros son "cabros del río", y otros pueden haber ascendido al grado de "cargadores" o "choros", entre otros varios escalafones del orden social fluvial (162). Como plantea Diamela Eltit, los niños del río son "cuerpos desnudos de la ideología burguesa, atienden a sus propios códigos que no resultan menos rígidos que los que transitan por los sistemas oficiales" ("Género y poder" 90). La ciudad que identifica a los habitantes del río como "vagabundos" o "delincuentes" y, como tal, potenciales miembros de las aglomeraciones urbanas, desconoce esta serie 
de rangos que diferencian y estructuran internamente su población. Esos niños no son solo "chiquillos andrajosos" como se menciona en la escena citada al inicio de este artículo de Islas en la ciudad (171), sino que cada uno de ellos desempeña el papel que le ha sido designado por las autoridades del Mapocho. En ese sentido, en su propio contexto hay una conciencia de comunidad que tensiona la retórica de la intimidad burguesa expuesta en Islas en la ciudad.

En el río destaca una heterogeneidad social que está claramente jerarquizada $y$, desde la mirada de sus habitantes, se apartaria de la idea de multitud y "sociedad de masas" que señalé para las novelas de Sepúlveda Leyton. En este sentido, la sociabilidad y técnicas de sobrevivencia de los niños del río dependen de instancias de aprendizaje que se diferencian de los métodos a los que el narrador de La fábrica está sometido: "En las noches los líderes del río reunían a la muchachada y la hacían narrar sus aventuras del día. Se criticaban las actuaciones para perfeccionar los métodos y señalar errores. Era un foro. El grupo se informaba y aprendía técnicas" (280-81). Esto ocurría en la comunidad fluvial ¿Qué pasaba en la ciudad? Algo ya se ha mencionado a partir de la segunda novela de Sepúlveda Leyton. Sin embargo, quisiera incorporar lo que el historiador Rojas Flores en su libro Moral y prácticas cívicas en los niños chilenos, 1880-1950, citado también al inicio de este artículo, reconstruye y estudia los "mecanismos de educación cívica" dirigidos a los niños para su formación política. De su investigación, junto con otros espacios y asociaciones de instrucción, destaco los programas, manuales y rituales que fueron impartidos, leídos y practicados en especial dentro de la escuela. Según el historiador, dentro y fuera del sistema escolar niños y niñas eran sometidos a prácticas de incorporación como forma de asegurar su correcta inserción social en tanto futuros ciudadanos. Si bien la novela de Gómez Morel se publica en los años sesenta, si nos atenemos estrictamente a su carácter autobiográfico, la infancia de Toño transcurre entre las décadas de los veinte y los treinta cuando, según Rojas, las políticas de instrucción cívica están en plena vigencia. No es sino hasta la década del cuarenta cuando el investigador nota una disminución de la presencia de escolares en los rituales cívicos santiaguinos si se compara con las primeras décadas del siglo XX. Desde entonces, pasaron a ser más espectadores que actores, señala el historiador de la infancia chilena (93). Sin embargo, en la cuenca del río se revela el fracaso de estas prácticas en la incorporación de los niños en la institucionalidad ciudadana: los habitantes del río no quieren pertenecer a la ciudad ni ser ciudadanos. Entonces, inventan su propio mundo, El río es "la historia de la fascinación por ese mundo agreste como un espacio extramuros donde es posible obtener todo lo negado por las instituciones de la ciudad: libertad, afecto, solidaridad" (Vicuña 107).

A medida que transcurre la novela, la cuenca del Mapocho se va transformando ante los ojos del niño-delincuente-narrador. Toño va construyendo a su antojo el paisaje que a la vista de los ciudadanos es miserable e infesto. Cuando el niño empieza a familiarizarse con la cotidianidad del río, sus ritos y su organización político-social, el paisaje y las costumbres son dotados de atributos que transportan al lector a otro espacio y otra temporalidad. Los pelusas se "sientan en rueda" para comentar los sucesos del día (104), 
para celebrar un triunfo de su jefe, el Zanahoria, lanzan "aullidos interiores" como si fueran lobos (139); el techo que cobija a Toño en las noches llamado inicialmente casucha pasa a ser llamado "choza" (143). El lenguaje utilizado para crear esta escena recuerda la cotidianidad de una tribu. Siguiendo las ideas de Diana Taylor de su libro Archivo y repertorio, los niños del río realizan una performance tribal mediante la que transmiten una forma de habitar el mundo: hacerle la guerra a la ciudad. Paul Connerton, citado por Taylor en su libro Performance, identifica en las culturas indígenas originarias de América "'prácticas de incorporación' que se internalizan en el mismo cuerpo (la sonrisa, el saludo, la interacción personal que comunica algo [...]" y por medio de estas se "ensayaban y memorizaban códigos culturales" (Taylor Performance 53). En la cuenca del Mapocho se aprende a odiar a la ciudad: "pero nuestra solidaridad con el Zanahoria no era por él mismo, sino por nuestro común sentimiento contra la ciudad. Nuestro jefe explotaba el odio común" (166). Si bien Toño no es convocado ni buscado por los pelusas del río, en su convivencia aparentemente las "prácticas de incorporación" funcionan para generar un sentido de pertenencia. En la novela de Gómez Morel, ante la inminencia del combate directo contra la ciudad, el protagonista expresa: "[...] me sentí Río, totalmente Río. Me identifiqué con todos los delincuentes [...] Los sentí hermanos, como si hubiesen sido los únicos seres respetables por los que se debía luchar. Recuerdo que miré hacia la ciudad y escupí despectivamente" (170). Un espacio compartido tanto geográfico como cultural, la imitación de una forma de comportamiento, el aprendizaje de ser "Río" y un sentimiento de lealtad generan en el niño un sentido de comunidad que, sin embargo, no es recíproco. Toño nunca será totalmente aceptado por las autoridades del mundo fluvial.

En la novela El río, "la loca de la casa" enriquece el repertorio que se hace presente en la vida fluvial. Continuando con la idea de performance, la ficción autobiográfica que cruza la novela enriquece el repertorio que se hace presente en la vida fluvial. En el río se vive de forma tribal, pero también otros sistemas políticos se hacen presentes haciendo un juego con otras geografías así como con otros tiempos históricos. Al conocer al jefe máximo del Río, el Zanahoria, se creyó "un indiecillo humilde e insignificante que por casualidad se enfrenta en la calle con su Inca" (141); inmediatamente después, tras ser temporalmente aceptado por el jefe máximo, el Zanahoria, señala "[m]e sentí como si en ese instante me hubiese armado Caballero del Río" (143) y, por último, en una escena en que están rodeados por la policía el niño narrador señala "[t]odos nos fuimos acercando. Parecíamos una caravana de esclavos egipcios. La ciudad nos miraba, formando larga fila en la orilla" (172). "Creerse", "sentirse como", "parecerse", todas estas palabras enfatizan el "no ser", sino el "imaginar ser", es decir, una ficcionalización que fortalece la idea de performance que subyace en la vida de los habitantes del Río. Según Taylor "las performances operan como actos vitales de transferencia, transmitiendo el saber social, la memoria y el sentido de identidad a partir de acciones reiteradas" (Performance 22). Todas las citas de la novela El río mencionadas recientemente enfatizan sistemas sustentados bajo un mismo principio ordenador que es jerárquico, servil y masculino. Estos se repiten en momentos específicos de la historia universal y se incorporan en la narración como formas de organización alternativas que, asimismo, funcionan como espejo del orden de la ciudad contemporánea. 
$\mathrm{Si}$, siguiendo las ideas de Rojas, los rituales cívicos eran el mecanismo para incorporar y disciplinar a los futuros ciudadanos dentro del sistema institucional de la ciudad, en el río, el ejercicio del ritual (y la imitación) no desaparece, sino que, operando de otra forma, parainstitucional, resistente y desde la frontera en la que se constituye el río Mapocho, triunfa al generar un sentido de pertenencia en Toño, a diferencia de su fracasada experiencia en el sistema escolar. De todos modos, distinta es la experiencia de la educación formal en el caso de Juan de Dios en la novela La fábrica, quien, finalmente, se convierte en un profesor normalista. Considerando la idea de los rituales cívicos a los que niños como Juan de Dios estuvieron expuestos, quisiera señalar también que la metodología de la enseñanza primaria de la primera mitad del siglo XX incorpora de forma consistente las dramatizaciones. En los programas de los años 1931 y 1949 y en los materiales escolares, es recurrente en su planificación las dramatizaciones tanto de la vida de los indígenas y de otras culturas como de hechos históricos violentos y heroicos de la historia regional y nacional (Dirección General de Educación Primaria). El descubrimiento de América como también la vida indígena se aprende por medio de la dramatización (Dirección General, Exposición pedagógica ambulante, 9-1). Los niños en la enseñanza primaria no solo debían repetir un modelo de ciudadano como el protagonista de La fábrica, sino también representaban la lucha entre españoles e indígenas, entre criollos y realistas, y entre chilenos y peruanos. Por un lado, estos planes de la enseñanza primaria, al parecer, naturalizan la violencia y la guerra y las jerarquías entre seres superiores e inferiores en cuanto condiciones propias de la historia nacional o continental. Por otro, ponen en circulación un imaginario sobre la guerra y, con ello, la transmisión de un ideal de masculinidad asociado al heroísmo, que se construye en oposición a un enemigo, y al uso de la fuerza y de la violencia. En este sentido, el estado de guerra y los modelos de masculinidad asociados a la enseñanza de la historia de estos programas no parecen tan distantes del espíritu combativo de la comunidad fluvial y de los papeles que asumen en su cotidianidad: "caballero", "indiecillo humilde" y "esclavos". De este modo, aunque la formación cívica no fue exitosa en los niños que huyeron para habitar en la cuenca del Mapocho, aquellos que pasaron por la escuela aprendieron jugando a ser otros sujetos inscritos en la historia nacional o universal.

Me parece interesante destacar la idea de imitación y repetición que refuerza la presencia de la performance en el proceso de aprendizaje y crecimiento de los niños. En cuanto a esto último, en el caso de Hijuna y La fábrica, la performance produce ciudadanos útiles, pero carentes de subjetividad, en el caso de El río, ocurre lo contrario, los niños se desmarcan de la ciudad y en su mundo delictual son potenciales héroes de otros tiempos y espacialidades. Al final de la novela, un Toño ya adolescente y decepcionado por no lograr ser un integrante permanente del río concluye buscando nuevos caminos para afirmar su identidad delictual: "Sentía odio y asco por todo lo que fuese ciudad, sociedad y ser humano. Quería seguir robando" (338-339).

La infancia suele vincularse a un estadio "primitivo" del hombre, el que es, a su vez, asociado a las multitudes del cambio de siglo. La barbarie de la infancia en el río se refuerza al inscribirse en un espacio que es, aparentemente, pura naturaleza. Los pelusas del Río, como sujetos en rebeldía 
dejan el artificio urbano para residir en un supuesto espacio natural, no domesticado ni civilizado, en el cual pueden performar su propia organización política, social y cultural. Sin embargo, y a diferencia de las representaciones del roto en las que prima el cuerpo, su exhibición y su brutalización, en la novela de Gómez Morel, el mundo fluvial y sus habitantes, estos posibles miembros de las masas urbanas, que según De Ramón y Romero protagonizan la historia social y urbana del siglo XX, más que cuerpos brutalizados son sujetos recicladores de historias, productores de una ficción que deviene en resistencia. Son niños jugando a inscribirse en la historia de la civilización, condensando en el presente varios pasados "gloriosos": "Teníamos nuestro personaje heroico" dice con orgullo el niño narrador al referirse a su jefe (139). En su ensayo "El país de los juguetes. Reflexiones sobre la historia y el juego" Giorgo Agamben, haciendo referencia a la "infancia como dimensión originaria de lo humano" (89) plantea que "[u]n vistazo al mundo de los juguetes muestra que los niños ... juegan con cualquier antigualla que les caiga en las manos y que el juego conserva así objetos y comportamientos profanos que ya no existen" (101). Además, arguye Agamben, "el juego ... es una máquina que transforma la sincronía en diacronía" en tanto destruye "la conexión entre pasado y presente" (107). De este modo, en el juego no se cuestiona la copresencia de figuras como caballeros (medievales), incas y esclavos egipcios que, fuera del juego, eran reproducidas por la ciudad en revistas, libros, enciclopedias, historietas y películas. Los niños de la capital chilena durante la primera mitad del siglo XX si no tuvieron acceso a la educación primaria donde forjaron un imaginario sobre otras civilizaciones, probablemente estuvieron expuestos a otras imágenes similares que circularon en las revistas infantiles, en películas y sus anuncios, y en periódicos, entre otros registros de los medios de comunicación masivos. En una revisión de la revista Simbad (1949-1956) es posible constatar que las historietas que se publicaban, muchas de ellas traducciones del mercado editorial estadounidense, se nutren también de hitos de la historia universal y de procesos de conquista y colonización tanto americanos como de otras áreas culturales. En estas historietas destacan personajes como Hernán Cortés, caballeros de la época del rey Arturo, Tarzán, Búfalo Bill, entre otras figuras masculinas "blancas" y "subalternas" que se encuentran en la América y África misteriosas, bárbaras y exóticas. Se arguye entonces, que el mundo del río imaginado por Toño está mediado por la "cultura de masas" entendida como "un vehículo privilegiado de socialización" que "profundiza la deslocalización de las personas" (Ortiz 102). "Los objetos de interés de las masas atraen la atención de las personas hacia fuera de sus culturas locales, así como de las esferas de la vida cubiertas por normas, reglamentos y expectativas", señala Ortiz (103). Sin embargo, por otra parte, como plantea Jeftanovic para la obra de teatro Gemelos basada en la novela El gran cuaderno de Agota Kristóf y montada por la compañía La Troppa en los noventa, el juego puede ser una forma de escapar de la realidad: "en tanto sujetos niños, se refugian en la actividad lúdica para compensar estas dolorosas experiencias" (49).

Tanto Juan de Dios como Toño se inscriben en procesos de masificación el primero, participa de las multitudes o masas que protestan contra las medidas del gobierno de inicios de siglos y que, luego, son incorporados al cuerpo ciudadano ideal por medio de un proceso de homogeneización administrado por los aparatos del Estado. Gracias a la institucionalidad 
educativa, se convierte en un profesor normalista, un sujeto más de la producción ciudadana del Estado. El segundo se inscribe en la multitud en tanto es parte de la población que deambula por las calles de la ciudad y que habita los márgenes, como la cuenca del Mapocho y que se resiste a los procesos de escolarización y formación ciudadana. No obstante, construye identidades permeadas por la incipiente industria cultural. Por medio de la cultura de masas, Toño tiene la posibilidad de dejar de ser parte de una masa amorfa y oscura para, eventualmente, convertirse en un héroe dentro del mundo delictual. Si Juan de Dios recurre a "la loca de la casa" para sobrellevar el proceso de manufactura que opera en su subjetividad, en el caso de Toño, la "loca del casa" lo transporta al pasado para sobrevivir el presente.

\section{Obras citadas}

Agamben, Giorgio. Infancia e historia. Destrucción de la experiencia y origen de la historia. Buenos Aires: Adriana Hidalgo editora, 2007.

Dirección General de Educación Primaria (Ministerio de Educación Pública). Exposición pedagógica ambulante de trabajos y material escolar. Santiago de Chile: Imprenta Lagunas y Quevedo Ltda., 1929.

Dirección General de Educación Primaria (Sección pedagógica). Programas de Educación Primaria. Santiago de Chile: Imprenta Lagunas y Quevedo Ltda., 1931.

Dirección General de Educación Primaria (Ministerio de Educación Pública). Planes y programas de estudio para la educación primaria. Santiago de Chile: La Dirección, 1949.

Edwards Bello, Joaquín. El roto. 17a ed. Santiago: Editorial Universitaria, 2000.

Eltit, Diamela. "Género y poder". Emergencias. Escritos sobre literatura, arte y política. Santiago: Editorial Planeta, 2000. 79-103.

Gertner, María Elena. Islas en la ciudad. 2a. ed. Santiago: Editorial del Nuevo Extremo, 1958

Gómez Morel, Alfredo. El río. Santiago de Chile: Talleres de Arancibia Hnos, 1962.

Jeftanovic, Andrea. Hablan los hijos. Discursos y estéticas de la perspectiva infantil en la literatura contemporánea. Santiago: Editorial Cuarto Propio, 2011.

Montaldo, Graciela. "Hombres de la multitud y hombres de genio en el finde-siècle". Entre hombres. Masculinidades del siglo XIX en América Latina. Ana Peluffo e Ignacio M. Sánchez Prado, eds. Madrid: Frankfurt: Iberoamericana / Vervuert. 123-144.

Ortiz, Renato. Otro territorio. Ensayos sobre el mundo contemporáneo. Buenos Aires: Universidad Nacional de Quilmes, 1996.

Rojas Flores, Jorge. Moral y prácticas cívicas en los niños chilenos, $1880-$ 1950. Santiago: Ariadna Ediciones, 2004.

Sepúlveda Leyton, Carlos. "Hijuna". Trilogía normalista. Santiago: Sangría Editora, 2013. 13-182.

. "La fábrica". Trilogía normalista. Santiago: Sangría Editora, 2013. 221-445.

Simbad. [Santiago: Editorial Zig-Zag] Nov. 1949- Ago. $1951<\mathrm{http}: / / w w w$. sepiensa.cl/edicion/index.php?option=content\&task=view\&id=188> 
Subercaseaux, Bernardo. Historia de las ideas y de la cultura en Chile. Nacionalismo y cultura. Tomo IV. Nacionalismo y cultura. Santiago de Chile: Editorial Universitaria, 2007.

Taylor, Diana. Performance. Buenos Aires: Asunto Impreso ediciones, 2012 The Archive and the repertoire. Performing Cultural Memory in the Americas. Durham and London: Duke University Press, 2003. 
